\title{
Sistematização da Hemovigilância em Hospital Geral
}

Autores: RODRIGUES, Andréia Leão Rodrigues; ANACLETO, Alexandre Augusto Rabazallo; SILVA, Luiz Sérgio Almeida

\section{Introdução:}

A terapia transfusional é um processo que envolve riscos sanitários mesmo que realizado em condições apropriadas e obedecendo as normas preconizadas. A probabilidade de ocorrerem efeitos adversos imediatos é de $90 \%$ e tardios de 10\%, por isso, a qualidade e a segurança devem permear todas as etapas do processo. A hemovigilância se insere neste contexto, como um sistema de alerta e avaliação para prevenir o aparecimento dos efeitos adversos ou sua recorrência.
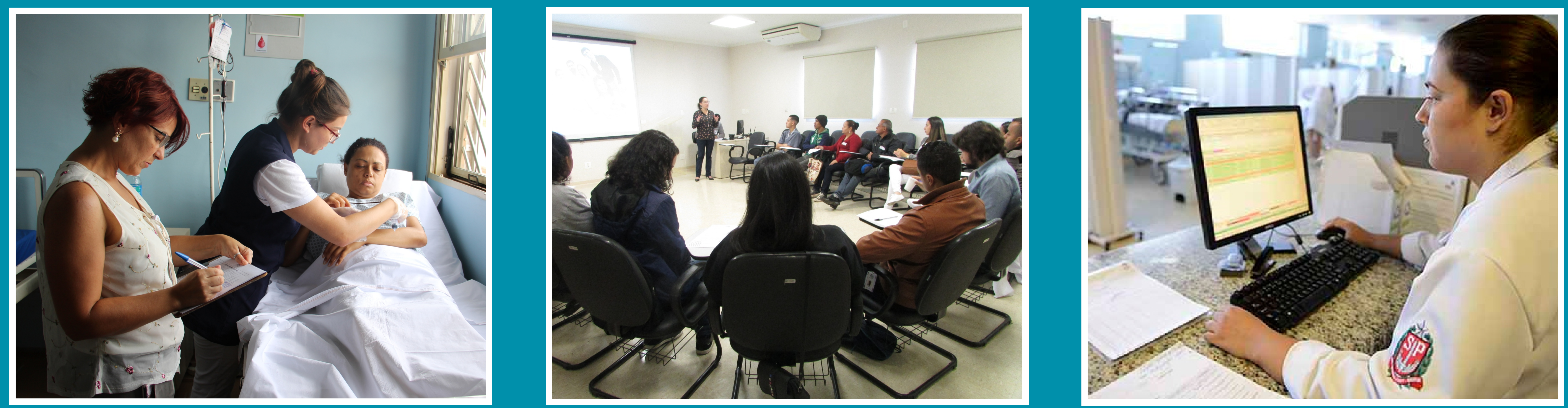

\section{Objetivo:}

Com os objetivos de melhorar o monitoramento do processo transfusional garantindo sua rastreabilidade, aumentar a detecção de prováveis reações transfusionais e integrar a Hemoterapia na multidisciplinaridade no atendimento ao paciente, implantou-se um pacote de medidas junto da sistematização da hemovigilância no prontuário eletrônico.

\section{Método:}

O pacote de medidas contemplou a educação continuada das equipes, informações integradas no prontuário eletrônico e acompanhadas em real time entre as áreas atuantes, parametrização de alertas no sistema eletrônico, implantação de trigger tool para identificação de casos,

checagem beira leito pós-transfusão, sistema de notiflcação dos eventos /quase-eventos e disseminação da cultura de segurança.

\section{Conclusão}

Conseguiu-se aumentar o número de notificações de casos suspeitos de reações transfusionais em mais de 50\% após o pacote de medidas. Portanto, a construção de um serviço de qualidade depende do envolvimento e do esforço coletivo, é necessário fortalecer continuamente a integração entre as equipes com foco no aperfeiçoamento da qualidade da assistência prestada e a tecnologia é uma ferramenta importante na otimização dos processos. 